\title{
Fusarium oxysporum Strains as Potential Striga Mycoherbicides: Molecular Characterization and Evidence for a new forma specialis
}

\author{
Abuelgasim Elzein ${ }^{*}, 1$, Frank Brändle ${ }^{2}$, Georg Cadisch $^{1}$, Jürgen Kroschel ${ }^{3}$, Paul Marley ${ }^{4}$ and \\ Marco Thines ${ }^{*}, 2$
}

${ }^{1}$ Institute for Plant Production and Agroecology in the Tropics and Subtropics (380), University of Hohenheim, D-70593 Stuttgart, Germany

${ }^{2}$ Institute of Botany (210), University of Hohenheim, D-70593 Stuttgart, Germany

${ }^{3}$ Integrated Crop Management Division, International Potato Center (CIP), Av. La Molina 1895, Apartado 1558, Lima 12, Peru

${ }^{4}$ Department of Crop Protection, Faculty of Agriculture/Institute for Agricultural Research, Ahmadu Bello University, Zaria, Nigeria

\begin{abstract}
Fusarium oxysporum isolates (Foxy 2 and PSM197) are potential, highly host specific mycoherbicides for the control of the parasitic weeds Striga hermonthica and S. asiatica. Their target weeds, Striga spp., are major biotic constraints in cereal and legume production in semi-arid tropical Africa, where they adversely affect livelihood of millions of subsistence farmers. The aim of this study was to characterize and sequence the Striga mycoherbicides Foxy 2 \& PSM197 in order to more clearly distinguish them from other morphologically similar pathogenic Fusarium oxysporum strains. The fungal isolates were cultivated on PDA medium and characterized based on the analysis of partial DNA sequence of the internal transcribed spacer (ITS) regions of the nuclear ribosomal RNA gene. Both isolates were identical in their ITSsequence. The unique and identical ITS-sequence of the two isolates obtained, compared to the sequences of Fusarium oxysporum forma speciales deposited in GenBank along with the host specificity to Striga demonstrated in previous studies, provides strong evidence to propose these pathogens of Striga as a new forma specialis (f. sp. strigae). The possibility to clearly distinguish between the new forma specialis and all pathogenic Fusarium oxysporum strains sequenced so far will facilitate and encourage the acceptance and introduction of Striga-mycoherbicides for practical field application by regulatory authorities and farmers.
\end{abstract}

Keywords: Weed biocontrol, mycoherbicides, host specificity, bio-safety, ITS sequence, Striga hermonthica.

\section{INTRODUCTION}

Globally, root parasitic weeds of the genus Striga, particularly $S$. hermonthica (Del.) Benth., have a greater impact on human welfare than any other parasitic angiosperm, because their hosts are cereal crops of subsistence farmers in areas marginal for agriculture in the Sahelian and the Savannah zones of Africa. In infested areas, yield losses associated with S. hermonthica infestation on sorghum (Sorghum bicolour (L.) Moench) and maize (Zea mays L.) are often significant, ranging from 40 to $100 \%$ [1-3], and aggravate hunger and poverty. Control of Striga is particularly difficult due to its special biology and intimate physiological interaction with its hosts. In addition, significant damage is done to the host before parasite shoots emerge from soil. So far, no economically feasible single method can solve the problem, and therefore an integrated approach, in which biocontrol could

\footnotetext{
*Address correspondence to these authors at the (AE) Institute for Plant Production and Agroecology in the Tropics and Subtropics (380), University of Hohenheim, D-70593 Stuttgart, Germany; Tel: +49-711-45924346; Fax: +49-711-45922304; E-mail: gasim@uni-hohenheim.de and (MT) Institute of Botany (210), University of Hohenheim, D-70593 Stuttgart, Germany; Tel: +49-711-45923331; Fax: +49-711-45923355; E-mail: thines@uni-hohenheim.de
}

be a crucial component, appears to be the most promising strategy for reducing Striga infestations.

Mycoherbicides are particularly attractive, since they can be weed-specific, have low environmental impact and are often cost-effective [4]. Biological control of S. hermonthica by soil application of a mycoherbicide containing Fusarium oxysporum Schlecht., has been reported to have several advantages. It attacks the target weed before emergence [5-8], just before most of the damage to the host occurs. This reduces the Striga seed bank in the soil, prevents production of new seeds and increases the grain yield of the crop in the same cropping season. Additionally, it is assumed to be cost-effective, requiring no changes in crop rotation and, if applied as a seed treatment, no additional labour is needed [9]. Two fungal stains, Foxy 2 and PSM197 of $F$. oxysporum, isolated from diseased S. hermonthica plants from Ghana and Nigeria, respectively, are specific towards their hosts, highly aggressive against all developmental stages of $S$. hermonthica including seeds and can be mass-produced using agricultural by-products $[7,8,10$, 11]. Thus, these fungal isolates are well suited to be developed into a specific mycoherbicide, to support and enhance the existing Striga control measures. Both isolates exhibited potential efficacy in controlling $S$. hermonthica and improving crop performance under controlled and field conditions of West 
Africa when developed into Pesta granular formulations or delivered as seed treatment on crops [9, 12-14]. Further, both mycoherbicides maintained excellent viability on Pesta products and treated seeds after one year of storage, sufficient for their use under practical conditions of storage, handling and delivery $[9,15]$.

The acceptance and implementation of inundate biological control by regulatory authorities are based on safety issues which include avoidance of any non-target adverse effects associated with the use of biological control agents whether the agent be indigenous or non-indigenous, naturally occurring or genetically modified. It is very important that host specificity testing and risk assessment methodologies should both lead to prevention of the release of any organism that is likely to have detrimental impacts on non-target plants or on environment. Several approaches have been used to provide the required information for proper risk assessment including: quantifying the relative susceptibility of the target and non-target plant species [16]; microscopic and histological examination of infection events [17]; measuring relative plant damage [18]; morphological and molecular comparisons between foreign and indigenous organisms [19]; and epidemiology [20]. In two studies $[10,21]$ it was shown that the Striga pathogenic strains Foxy 2 and PSM197 are nonpathogenic to all sorghum varieties tested and also to all other crops tested. Among these were 25 (for Foxy 2) and 17 (for PSM197) non-target plant species including cereals, legumes, fruits, vegetables, oilseeds and fibrous crops. To further investigate the possibility that the two strains might be a new forma specialis, a molecular phylogenetic approach was used to characterize the two potential mycoherbicide strains.

Molecular markers have proven to be powerful tools for the characterization and identification of several plant pathogenic fungi. With the advent of polymerase chain reaction (PCR), inexpensive DNA sequencing, and a relatively large databank of ribosomal DNA sequences, it is now possible to more objectively characterize and identify fungal species on the basis of sequence stretches commonly used for calculating molecular phylogenies or for identifying pathogens. Among these sequences are different regions of the nuclear ribosomal DNA (nrDNA) cistron, in particular the internal transcribed spacers [22], of which numerous sequences from $F$. oxysporum isolates are deposited in GenBank. The objective of this study was to characterize and sequence the potential Striga mycoherbicides Foxy 2 and PSM197 in order to test, if they can be clearly distinguished from other morphologically similar pathogenic $F$. oxysporum strains.

\section{MATERIALS AND METHODS}

\section{Origin of Fungal Isolates}

The isolates Foxy 2 and PSM197 used for this study were obtained from severely diseased $S$. hermonthica collected in North Ghana [5] and in Samaru, Nigeria [8], respectively. Taxonomic identification of the isolates was confirmed by the Federal Biological Research Centre for Agriculture and Forestry, Berlin, Germany, for Foxy 2, where the isolate was deposited under accession number BBA-67547-Ghana, and the International Mycological Institute (IMI), Egham, UK, for PSM197 which is deposited at Medical Research Council, Tygerberg, South Africa under accession number MRC
8537. Since then the isolates were preserved on Special Nutrient poor Agar (SNA) medium [23] with 5\% (v/v) glycerol at $-40^{\circ} \mathrm{C}$ in the Institute of Plant Production and Agroecology in the Tropics and Subtropics, University of Hohenheim, Stuttgart, Germany. All investigations were performed with a single-spore isolate of either Foxy 2 or PSM197.

\section{Fungal Cultures}

Mycelial and conidial cultures of Foxy 2 and PSM197 were prepared on Potato Dextrose Agar (PDA) medium. Four PDA Petri-dishes (i.e. 4 replicates) were aseptically inoculated each with one agar disc $(\varnothing 0.6 \mathrm{~cm})$ of active growing fungal colony of Foxy 2 or PSM197. Additionally, four Petri-dishes (i.e. 4 replicates) were aseptically inoculated each with one sorghum seed coated with dried chlamydospores of Foxy 2 or PSM197 using Arabic Gum (40\%) as an adhesive [9] and placed in the centre of the Petri-dish. Thereafter, the inoculated Petri dishes were incubated in the dark at $25^{\circ} \mathrm{C}$ for 7 days.

\section{DNA-Extraction and PCR}

For DNA extraction, $5 \mathrm{mg}$ of hyphae of each of the samples were disrupted in a mixer mill (Reetsch, Germany) using two magnetic balls of $3 \mathrm{~mm}$ in diameter. DNA-extraction was done using the QIAquick Plant DNA extraction kit (Qiagen, Germany), according to the manufacturer's instructions. PCR was done on an Eppendorf Mastercycler (Eppendorf, Germany) using the universal primers ITS1 and ITS4 [24], with the conditions described there. The amplicons obtained were separated on $1 \%$ agarose gels, stained with ethidium bromide and cut from the gel using sterile scalpels. The PCR products were cleaned using the QIAquick GelExtraction Kit (Qiagen, Germany) according to the manufacturer's instructions. Sequencing was done by a commercial sequencing company (GATC, Germany) with the primers used for PCR amplification.

\section{Data Analysis}

Because a high sequence similarity was observed, alignments were done with clustalX, version 1.8 using the factory settings. From the alignment obtained, all gaps present in more than half the samples were removed. For molecular phylogenetic reconstruction, Mega 3.1 [25] was used. Gaps were treated as pairwise deletion. Minimum Evolution analysis was performed using the Tamura-Nei substitution model [26] and a starting tree obtained by Neighbor-joining [27], keeping only one of the best trees obtained. Maximum Parsimony analysis was done using the applicable parameters mentioned above. In both cases, all parameters not mentioned equalled the factory settings of the program. In both cases, 1000 bootstrap replicates [28] were conducted.

\section{RESULTS}

\section{PCR and Sequencing}

PCR resulted in bright, single fragments of about $680 \mathrm{bp}$ in length. Partial ITS sequence obtained from these fragments was 596 bp. The ITS sequences obtained were deposited in GenBank under accession numbers EU264073 and EU264074, for Foxy 2 and PSM197, respectively. A blast search [29] revealed a unique ITS-sequence of the two isolates compared to any other $F$. oxysporum sequence of com- 
parable length. Sequence similarity among $F$. oxysporum isolates was generally high (above $99 \%$ ).

\section{Molecular Phylogenetic Reconstructions}

The single best tree obtained by Minimum Evolution (ME) analysis is presented in Fig. (1). The topology of the consensus tree of the 435 most parsimonious trees with a tree length of 40 is in concordance with the major groups shown in the ME tree. The first and the second number above the branches indicate bootstrap support in Maximum Parsimony (MP) and ME analysis, respectively. Bootstrap values below 33 are not shown.

Sister-group relationship of $F$. oxysporum and F. subglutinans is well supported in both analyses performed. Within the Fusarium oxysporum, resolution was generally low and the support for the different lineages weak. However, the clade containing the new forma specialis and $F$. oxysporum f. sp. cubense as well as f. sp. radicis-lycopersici was found in $89 \%$ of the most parsimonious trees and was supported by a support value of 74 in interior branch tests for ME (data not shown). The other clades present in the majority consensus tree of the MP analysis were also present in the ME tree, although with lower frequency. Only the partition that received a bootstrap support of 53 in the ME analysis was not resolved in the MP consensus tree.

\section{DISCUSSION}

The mycoherbicides $F$. oxysporum Foxy 2 and PSM197 are highly pathogenic and host specific to $S$. hermonthica and non-pathogenic to a wide range of crops tested $[10,21]$. In addition, these strains do not produce any toxic compounds that present health risks [30]. Hence, these isolates are of great interest as promising potential mycoherbicide candidates for the control of Striga species. However, the safety of non-target cultivated and wild plants must be ensured prior to release of the agents in the field, irrespective of potential benefits of the biological control agents. Host specificity is an important part of risk assessments for plant pathogens in weed biocontrol, since its assessment is the best way of predicting both direct and indirect effects on nontargets [31]. Our recent results showed that the host range of Foxy 2 and PSM197 is restricted to the genus Striga, and none of the tested non-target plant species showed any symptoms of infection $[10,21]$. The tested species comprised some selected poaceous crops related to sorghum, crop species reported to be highly susceptible to Fusarium diseases in tropical and subtropical regions, as well as other economically important crops cultivated in the regions of Striga infestation. The category of the highly susceptible species to $F$. oxysporum diseases tested included: banana (Musa textilis Née), chickpea (Cicer arietinum L.), cotton (Gossypium barbadense Mill.), cucumber (Cucumis sativus L.), egg plant (Solanum melongena L.), faba bean (Vicia faba L.), okra (Abelmoschus esculentus (L.) Moench), pea (Pisum sativum L.), soybean (Glycine max (L.) Merr.), roselle (Hibiscus sabdariffa L.) and tomato (Lycopersicon lycopersicum (L.) Karsten ex Farw.). In other host-range studies, the indigenous $F$. oxysporum isolates from Burkina Faso, Mali and Nigeria were also found to infect only Striga spp. and none of the crops and vegetables tested [6, 32]. Those results confirm the restriction of pathogenicity of $F$. oxysporum isolated from Striga spp. to the target species.

The use of nrDNA sequences often allows unequivocal determination of fungal species [33]. In this study it was shown that it was possible to distinguish Foxy 2 and PSM197 from other morphologically similar, pathogenic $F$. oxysporum strains by ITS-sequencing, which is applicable for their routine identification. The ITS-sequence obtained from the two strains was not identical to any ITS-sequence deposited in GenBank, a fact that, in combination with their host specificity (so far infectiveness could only be demonstrated to species of Striga), clearly indicates that the two strains belong to a new forma specialis. The high similarity between the two isolates can be linked to their high specificity towards Striga and maybe their geographic origin [34].

Although the resolution of the phylogenetic reconstruction within $F$. oxysporum was generally low, it should be noted that the clade consisting of the two strains pathogenic to Striga and F. oxysporum f. sp. radicis-lycopersici as well as $F$. oxysporum f. sp. cubense was the only clade consistently supported, although with weak support, in both Minimum Evolution and Maximum Parsimony analyses. It is noteworthy that the highly susceptible target hosts of the most closely related formae specialis, $F$. oxysporum f. sp. radicis-lycopersici Jarvis \& Shoemaker (tomato) and $F$. oxysporum f. sp. cubense (E. F. Sm.) W. C. Snyder \& H. N. Hansen (banana) showed no symptoms after inoculation with Foxy 2 and PSM197, even at high levels of pathogen pressure $[10,21]$. Both hosts showed immunity to the new forma specialis and none developed any symptoms of disease infestation (e.g. wilting, dieback, necrosis and chlorosis normally caused by $F$. oxysporum). In addition, no direct or indirect negative effects on their vegetative growth parameters, including number of leaves, plant height, photosynthetic rate, and root and shoot biomass, were recorded after inoculation with Foxy 2 and PSM197. On the contrary, some positive effects on vegetative growth of tomato as a result of inoculation were observed. This demonstrated convincingly that tomato and banana are not hosts of the new forma specialis of F. oxysporum [10,21].

Gerlach and Nirenberg [35] have reported that Fusarium spp. are mostly specific at the host family or genus level, and such pathogens are taxonomically classified as formae speciales. Thus, the high specificity of the two isolates Foxy 2 and PSM197 to the genus Striga and their unique ITSsequence, which allows their molecular characterization, provides convincing evidence to propose these pathogens of Striga as a new forma specialis. This new forma specialis is named Fusarium oxysporum f. sp. strigae Elzein et Thines, f. sp. nova. The strain of Foxy 2, deposited at the Federal Biological Research Centre for Agriculture and Forestry, Berlin, Germany, under accession number BBA-67547Ghana, is designated here as the type culture of Fusarium oxysporum f. sp. strigae.

The possibility to characterize $F$. oxysporum f. sp. strigae by its host range and, perhaps even more important, by its unique ITS-sequence, will greatly improve the acceptance of its use as a mycoherbicide by farmers and officials, because it allows its unequivocal identification and differentiation compared with other $F$. oxysporum isolates so far sequenced. 


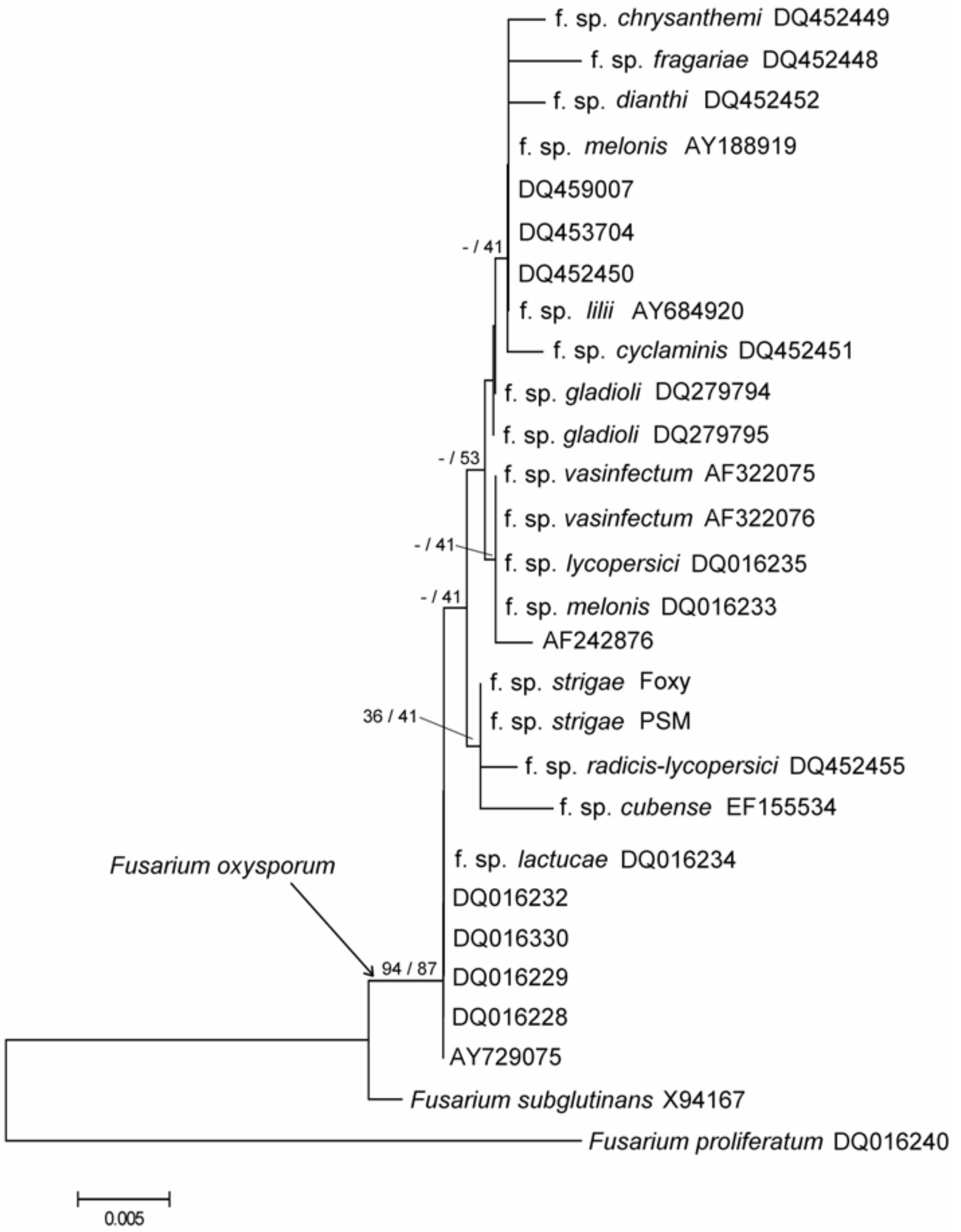

Fig. (1). Single best tree obtained by Minimum Evolution (ME) analyses of the nrITS of several Fusarium oxysporum isolates. The first and the second number above the branches indicate bootstrap support in Maximum Parsimony and ME analysis, respectively. Bootstrap values below 33 not shown. 


\section{ACKNOWLEDGEMENTS}

Financial supports by the Alexander von Humboldt Foundation $(\mathrm{AvH})$ and the Eiselen Foundation for Abuelgasim Elzein are gratefully acknowledged. Special thanks are due to Dr. Annerose Heller, Institute of Botany, University of Hohenheim, for enabling the collaborative work by bringing the parties involved in the present study together.

\section{REFERENCES}

[1] Bebawi FF, Farah AF. Effect of parasitic and non-parasitic weed on sorghum. Exp Agric 1981; 17: 337-41.

[2] Emechebe AM, Ellis-Jones J, Schulz S, et al. Farmers' perception of the Striga problem and its control in Northern Nigeria. Exp Agric 2004; 40: 215-32.

[3] Ejeta G. In: Ejeta G, Gressel J, Eds. Integrating new technology for Striga control: Towards ending the wicht-hunt. World Scientific Publishing Co. Pte. Ltd., UK. 2007; 3-16.

[4] Te Beest DO, Yang XB, Cisar CR. The status of biological control of weeds with fungal pathogens. Annu Rev Phytopathol 1992; 30: 637-57.

[5] Abbasher AA, Kroschel J, Sauerborn J. Microorganisms of Striga hermonthica in Northern Ghana with potential as biocontrol agents. Biocontrol Sci Technol 1995; 5: 157-62.

[6] Ciotola M, Waston AK, Hallett SG. Discovery of an isolate of Fusarium oxysporum with potential to control Striga hermonthica in Africa. Weed Res 1995; 35: 649-55.

[7] Kroschel J, Hundt A, Abbasher AA, Sauerborn J. Pathogenicity of fungi collected in Northern Ghana to Striga hermonthica. Weed Res 1996; 36: 515-20.

[8] Marley PS, Ahmed SM, Shebayan JAY, Lagoke STO. Isolation of Fusarium oxysporum with potential for biocontrol of the witchweed in the Nigerian Savanna. Biocontrol Sci Technol 1999; 9: $159-63$.

[9] Elzein A, Kroschel J, Leth V. Seed treatment technology: an attractive delivery system for controlling root parasitic weed Striga with mycoherbicide. Biocontrol Sci Technol 2006; 16(1): 3-26.

[10] Elzein A, Kroschel J. Host range studies of Fusarium oxysporum "Foxy 2": An evidence for a new forma specialis and its implications for Striga control. J Plant Dis Protect 2006; Suppl 20: 875-87.

[11] Elzein A, Kroschel J. Influence of agricultural by-products in liquid culture on chlamydospore production by the potential mycoherbicide Fusarium oxysporum Foxy 2. Biocontrol Sci Technol 2004; 14(8): 823-36.

[12] Elzein A, Kroschel J. Development and efficacy of granular formulations of Fusarium oxysporum "Foxy 2" for Striga control: an essential step towards practical field application in Africa. J Plant Dis Protect 2006; Suppl 20: 889-905.

[13] Schaub B, Marley P, Elzein A, Kroschel J. Field evaluation of an integrated Striga management in Sub-Saharan Africa: Synergy between Striga-mycoherbicides (biocontrol) and sorghum and maize resistant varieties. J Plant Dis Protect 2006; Suppl 20: 691-9.

[14] Elzein A, Fen B, Avocanh A, Kroschel J, Marley P, Cadisch G. Synergy between Striga-mycoherbicides Fusarium oxysporum f. sp. strigae and resistant cultivars under field conditions: Step towards integrated Striga control in Africa. In: Westwood J, Ed. Proceeding of the ${ }^{\text {th }}$ World Congress on Parasitic Plants; 2007 June 37; Omni Hotel, Charlottesville, Virginia, USA; 2007; pp. 76; [cited 2007 Dec 15]. Available from: http://www.cpe.vt.edu/wcopp/

[15] Elzein A, Kroschel J, Müller-Stöver D. Optimization of storage conditions for adequate (long) shelf-life of "Pesta" formulation of Fusarium oxysporum "Foxy 2", a potential mycoherbicide for Striga: effects of temperature, granule size and water activity. Biocontrol Sci Technol 2004; 14(6): 531-44.
[16] Bruckart WL, Politis DJ, Defago G, Rosenthal SS, Supkoff DM. Susceptibility of Carduus, Cirsium and Cynara species artificiallyinoculated with Puccinia carduorum from musk thistle. Biol Control 1996; 6: 215-21.

[17] Watson AK. Host range of, and reaction to Subanguina picridis. J Nematol 1986; 18: 112-20

[18] Shishkoff N, Bruckart WL. Evaluation of infection of target and non-target hosts by isolates of the potential biocontrol agent Puccinia jaceae that infect Centaurea spp. Phytopathology 1993; 83: 894-98.

[19] Wood AR, Crous PW. Morphological and molecular characterization of Endophyllum species on perennial asteraceous plants in South Africa. Mycol Res 2005; 109:387-400.

[20] DeJong MD, Scheepens PC, Zadoks JC. Risk analysis for biological control: A dutch case study in biocontrol of Prunus serotina by the fungus Chondrostereum purpureum. Plant Dis 1990; 74: 18994.

[21] Marley PS, Kroschel J, Elzein A. Host range of Fusarium oxysporum (isolate PSM 197) to be used as a mycoherbicide for the control of Striga hermonthica in West Africa. Niger J Bot 2006; 19(1): 17-28

[22] Paavanen-Huhtala S, Hyvoenen J, Bulat SA, Yli-Mattila T. RAPDPCR, isozyme, rDNA RFLP and rDNA sequence analyses in identification of Finnish Fusarium oxysporum isolates. Mycol Res 1999; 103: 625-34

[23] Nirenberg HI. Untersuchungen über die morphologische und biologische Differenzierung in der Fusarien Sektion Liseola. Mitt Biol Bundesanstalt Land- und Forstwirtsch, Berlin-Dahlem, Germany 1976; 196: 1-117.

[24] White TJ, Bruns T, Lee S, Taylor J. In: Innis MA, Gelfand DH, Shinsky JJ, White TJ, Eds. PCR Protocols: A Guide to Methods and Applications. Academic Press, San Diego, Canada. 1990; 31522

[25] Kumar S, Tamura K, Nei M. MEGA3: Integrated software for molecular evolutionary genetics analysis and sequence alignment. Brief Bioinform 2004; 5(2): 150-63.

[26] Tamura K, Nei M. Estimation of the number of nucleotide substitutions in the control region of mitochondrial DNA in humans and chimpanzees. Mol Biol Evol 1993; 10: 512-26.

[27] Saitou N, Nei M. The neighbour-joining method: a new method for reconstructing phylogenetic trees. Mol Biol Evol 1987; 4: 406-25.

[28] Felsenstein J. Confidence limits on phylogenies: an approach using the bootstrap. Evolution 1985; 39: 783-91

[29] Altschul SF, Madden TL, Schäffer AA, et al. Gapped BLAST and PSI-BLAST: a new generation of protein database search programs. Nucleic Acids Res 1997; 25: 3389-402.

[30] Amalfitano C, Pengue R, Andolfi A, Vurro M, Zonno MC, Evidente A. HPLC analysis of fusaric acid, 10-11 dehydrofusaric acid and their methyl esters, toxic metabolites produced by weed pathogenic Fusarium species. Phytochem Anal 2002; 13(5): 277-82.

[31] Secord D, Kareiva P. Perils and pitfalls in the host specificity paradigm. Bioscience 1996; 46: 448-53.

[32] Abbasher AA, Hess DE, Sauerborn J. Fungal pathogens for biological control of Striga hermonthica on sorghum and pearl millet in West Africa. Afr Crop Sci J 1998; 6: 179-88.

[33] Namiki F, Shiomi T, Kayamura T, Tsuge T. Characterization of the formae speciales of Fusarium oxysporum causing wilts of cucurbits by DNA fingerprinting with nuclear repetitive DNA sequences. Appl Environ Microbiol 1994; 60(8): 2684-91.

[34] Assigbetse KB, Fernandez D, Dubois MP, Geiger JP. Differentiation of Fusarium oxysporum f. sp. vasinfectum races on cotton by random amplified polymorphic DNA (RAPD) analysis. Phytopathology 1994; 84: 622-6.

[35] Gerlach F, Nirenberg H. The genus Fusarium - a pictorial Atlas. Federal Biological Research Centre for Agriculture and Forestry, Berlin-Dahlem, Germany 1982. 